Research Article

\title{
Antimicrobial Activity of Thermocycled Polymethyl Methacrylate Resin Reinforced with Titanium Dioxide and Copper Oxide Nanoparticles
}

\author{
Rashin Giti (D), ${ }^{1}$ Kamiar Zomorodian $(D),{ }^{2}$ Maryam Firouzmandi (D), \\ Zahra Zareshahrabadi $\left(\mathbb{D},{ }^{4}\right.$ and Sedigheh Rahmannasab $\mathbb{1}^{5}$ \\ ${ }^{1}$ Department of Prosthodontics, Biomaterials Research Center, School of Dentistry, Shiraz University of Medical Sciences, \\ Shiraz, Iran \\ ${ }^{2}$ Basic Sciences in Infectious Diseases Research Center, Shiraz University of Medical Sciences, Shiraz, Iran \\ ${ }^{3}$ Department of Operative Dentistry, School of Dentistry, Shiraz University of Medical Sciences, Shiraz, Iran \\ ${ }^{4}$ Department of Medical Mycology and Parasitology, School of Medicine, Shiraz University of Medical Sciences, Shiraz, Iran \\ ${ }^{5}$ Student Research Committee, School of Dentistry, Shiraz University of Medical Sciences, Shiraz, Iran \\ Correspondence should be addressed to Kamiar Zomorodian; zomorodian@sums.ac.ir
}

Received 4 December 2020; Revised 14 January 2021; Accepted 19 January 2021; Published 31 January 2021

Academic Editor: Gianrico Spagnuolo

Copyright (c) 2021 Rashin Giti et al. This is an open access article distributed under the Creative Commons Attribution License, which permits unrestricted use, distribution, and reproduction in any medium, provided the original work is properly cited.

\begin{abstract}
Aims. This study aimed to evaluate the effect of $2.5 \%$ and $7.5 \%$ copper oxide $(\mathrm{CuO})$ and titanium dioxide $\left(\mathrm{TiO}_{2}\right)$ nanoparticles on the antimicrobial activity of thermocycled polymethyl methacrylate (PMMA) denture base material against standard strains of yeast and bacteria species. Material and Methods. In this in vitro study, 150 disk-shaped $(10 \times 2 \mathrm{~mm})$ specimens of heat-cured PMMA were prepared and divided into five groups $(n=30)$ to be reinforced with $2.5 \% \mathrm{CuO}, 7.5 \% \mathrm{CuO}, 2.5 \% \mathrm{TiO}_{2}$, or $7.5 \% \mathrm{TiO}_{2}$ nanoparticles and a control group (without nanoparticle). The specimens were thermocycled, and their antimicrobial activity was assessed against standard strains of yeast including Candida albicans and C. dubliniensis and oral bacteria species including Streptococcus mutans, S. sobrinus, S. salivarius, and S. sanguis. Data were analyzed with ANOVA and Tukey's post hoc tests $(\alpha=0.05)$. Results. Both concentrations of $\mathrm{CuO}$ and $\mathrm{TiO}_{2}$ nanoparticles had significant antimicrobial activity against $S$. salivarius, S. sanguis, and C. dubliniensis compared with the control group $(P<0.05)$. Significant differences existed between both $2.5 \%$ $(P=0.006)$ and $7.5 \% \mathrm{CuO}(P=0.005)$ and the control group against $S$. mutans. However, $\mathrm{TiO}_{2}$ groups were not significantly different from the control group against $S$. mutans. Concerning C. albicans, $7.5 \% \mathrm{TiO}_{2}$ was the only nanoparticle with significantly higher antimicrobial activity compared with the control group $(P=0.043)$. Conclusions. Both concentrations of $\mathrm{CuO}$ and $\mathrm{TiO}_{2}$ were effective antimicrobial agents against S. salivarius, S. sanguis, and C. dubliniensis, and the concentration of CuO was effective against $S$. mutans. Yet, $\mathrm{TiO}_{2}$ was not much effective. Regarding C. albicans, only $7.5 \% \mathrm{TiO}_{2}$ showed efficient antimicrobial activity.
\end{abstract}

\section{Introduction}

Despite the general decline of edentulism, the increasing elderly population are still facing this problem and increasingly require general dental prosthetic treatments [1]. Polymethyl methacrylate (PMMA) is among the most common structural materials used for the preparation of partial and complete removable dentures, with several desirable properties such as ease of processing, color and chemical stability, durability, cost-effectiveness, and light weight [2]. However, the associating drawbacks include polymerization shrinkage, low mechanical strength, susceptibility to microbial colonization, allergic reactions mainly due to monomer saturation, and degradation of mechanical properties [3].

Adhesion of microorganisms to the denture surface and biofilm formation cause local (e.g., denture stomatitis) and systemic infections (e.g., aspiration pneumonitis) [4, 5]. Surface roughness, porosity, continual denture wearing, and poor denture hygiene are some factors which contribute to 
the adhesion of microorganisms and biofilm formation on the surfaces of acrylic resins [6]. Despite the improvement in properties and aesthetics of these materials, microorganisms still grow vastly under the acrylic resin bases [7].

Among the most prevalent oral infections, denture-associated oral ulcers (like denture stomatitis) are seen in $73 \%$ of prosthodontic patients, most of which are due to Candida albicans [6]. Stomatitis can be generally prevented through oral hygiene and denture cleansing, but these simple procedures might be compromised for hospitalized and geriatric patients due to reduced motor dexterity, cognitive impairment, and memory loss. Besides, the common treatment plans, namely, nystatin, fluconazole, and amphotericin B, are short term [8].

There are numerous approaches to enhance the mechanical properties of acrylic appliances and decrease the risk of oral infections and dental caries. Recently, much interest has been directed to inorganic nanoparticles with novel and improved physical, chemical, and biological properties, phenomena, and functionality due to their nanoscale size [9]. Specifically-formulated metal oxide nanoparticles have good antimicrobial activity. Some of these nanoparticles are $\mathrm{TiO}_{2}, \mathrm{SiO}_{2}, \mathrm{CuO}, \mathrm{CeO}_{2}, \mathrm{Ag}$, and halloysite nanotube (HNTs), which are incorporated in many biomaterials to induce antimicrobial activity and improve mechanical behavior $[10,11]$. The behavior of nanoparticles depends on the size of particles [12].

Studies revealed that PMMA nanocomposite based on functionalized $\mathrm{TiO}_{2}$ nanoparticles has better mechanical and antibacterial characteristics, as well as high physicochemical stability, low cost, nontoxicity, and biocompatibility. Moreover, $\mathrm{TiO}_{2}$ nanoparticles are catalytic, stable, reliable, and cost-effective and most importantly have antimicrobial effect against C. albicans, Staphylococcus aureus, Pseudomonas aeruginosa, and Escherichia coli [13-15].

Meanwhile, copper nanoparticles have unique physical and chemical properties, besides low preparation cost, which make them widely applicable as heat transfer systems, antimicrobials, ultrastrong materials, sensors, and catalysts $[16,17]$. $\mathrm{CuO}$ nanoparticles are very active and their high surface-to-volume ratio allows them to easily interact with other particles and increase the antimicrobial efficiency. To use their antibacterial properties, $\mathrm{CuO}$ nanoparticles are incorporated in dental materials like resin composites as nanofiller to decline the polymerization shrinkage and bacterial adhesion on the surface and increase the dimensional stability and surface smoothness $[16,18]$.

Alrahlah et al. [8] reported that $\mathrm{TiO}_{2}$ nanoparticles $(1,2$, and $3 \mathrm{wt} \%$ ) improved the antimicrobial behavior of PMMA by reducing the bacterial viability. Copper, gold, titanium, silver and their oxide nanoparticles have antibacterial properties [19]. Amiri et al. [20] detected that nanocopper oxide was highly effective against the examined dental caries bacterial agents and less effective on three species of Candida. Hence, $\mathrm{CuO}$ nanoparticles were introduced as a candidate control agent for preventing dental caries and dental infections [20]. The study by Argueta-Figueroa et al. [18] showed that $\mathrm{Cu}$ nanoparticles had bactericidal effects against $S$. aureus, E. coli, and S. mutans. Another study showed that adding $\mathrm{TiO}_{2}$ and $\mathrm{SiO}_{2}$ nanoparticles $(0.5 \%$ and $1 \%)$ to PMMA imparted antimicrobial activity to the resins, which was more efficient under UVA exposure [14].

The effects of different nanoparticles have been investigated on the physical and antimicrobial properties of PMMA denture base resin. The present study was designed to compare the effect of two concentrations (2.5\% and $7.5 \%)$ of $\mathrm{CuO}$ and $\mathrm{TiO}_{2}$ nanoparticles on the antimicrobial activity of PMMA denture base material against standard strains of Candida (albicans and dubliniensis) and Streptococcus (mutans, sobrinus, salivarius, and sanguis) after thermocycling. The null hypothesis was that adding different concentrations of $\mathrm{TiO}_{2}$ and $\mathrm{CuO}$ nanoparticles would not influence the antimicrobial activity of thermocycled PMMA denture base resin.

\section{Materials and Methods}

2.1. Specimen Preparation. In this in vitro study, 150 heatcured PMMA specimens $(10 \times 2 \mathrm{~mm})$ were made with two different concentrations of $\mathrm{TiO}_{2}$ and $\mathrm{CuO}$ nanoparticles as $2.5 \%$ $\mathrm{TiO}_{2}, 2.5 \% \mathrm{CuO}, 7.5 \% \mathrm{TiO}_{2}, 7.5 \% \mathrm{CuO}$, and control group (without nanoparticles) ( $n=30$ per group). The concentrations of both nanoparticles were selected according to the previous studies [21, 22] and the dimensions of the specimens for the antimicrobial test were based on the ISO standard \#1567. To fabricate the PMMA specimens, 30 disk-shaped wax patterns $(10 \times 2 \mathrm{~mm})$ were invested in dental stone (Fujirock EP; GC, Leuven, Belgium). After the setting of stone, the flasks (61B Two Flask Compress; Handler Manufacturing, Westfield, NJ, USA) containing the wax patterns were opened and dewaxed in boiling water for 5 minutes. $\mathrm{TiO}_{2}$ nanoparticles powder (average size $=17 \mathrm{~nm}, 99.9 \%$ purity, Fanavaran Daneshgah, Isfahan, Iran) and $\mathrm{CuO}$ nanoparticles (average size $=40 \mathrm{~nm}, 99.9 \%$ purity, Fanavaran Daneshgah, Isfahan, Iran) were weighed by using an electronic balance (Ohaus Corporation, NJ 07058, USA) with accuracy of $0.0001 \mathrm{~g}$, for concentrations of $2.5 \%$ and $7.5 \%$. Then, they were mixed with monomer of polymethyl methacrylate (PMMA; SR Triplex Hot, Ivoclar Vivadent, Liechtenstein, Germany) in aseptic conditions. The resulting suspension was stirred by an ultrasonic homogenizer (BioLogics, Inc., Manassas, Virginia 20109, USA) to disperse the nanoparticles in the MMA monomer. Then, the monomer was mixed with PMMA powder in liquid:powder ratio of $1: 3$. Acrylic dough was packed into the mold spaces. After the polymerization, the flasks were cooled in water, opened, and the specimens were removed. Finishing of the specimens was done with silicon carbide discs (Grit 600) by a polishing machine (MetaServ 250 Grinder-Polisher, Buehler, Lake Bluff, IL, USA) at $250 \mathrm{rpm}$, followed by a cloth wheel and a $0.5 \mu \mathrm{m}$ diamond suspension. To apply the temperature changes, the acrylic specimens were subjected to 2000 thermal cycles in $5^{\circ} \mathrm{C}$ and then $55^{\circ} \mathrm{C}$ water.

2.2. Determination of Minimum Inhibitory Concentration (MIC). Minimum inhibitory concentrations of the $\mathrm{TiO}_{2}$ and $\mathrm{CuO}$ nanoparticles against the selected microorganisms were determined by using the broth microdilution method 
according to the guidelines of Clinical and Laboratory Standards Institute (CLSI). To determine the antifungal activities, serial dilutions of $\mathrm{TiO}_{2}$ and $\mathrm{CuO}$ nanoparticles (128 to $0.25 \mu \mathrm{l} \mathrm{mL} \mathrm{m}^{-1}$ ) were prepared in 96-well microtiter plates by using RPMI-1640 media (Sigma, St. Louis, USA) buffered at pH 7.0 with 3-( $\mathrm{N}$-morpholino)propane sulfonic acid (Sigma, St. Louis, USA). Stock inoculum suspensions of the yeast and bacteria were prepared by suspending their colonies in $5 \mathrm{~mL}$ sterile $0.85 \% \mathrm{NaCl}$ and the turbidity of the suspensions was adjusted to $0.5 \mathrm{McF}$ arland standard at $530 \mathrm{~nm}$ wavelength by the spectrophotometric method to yield stock suspension of $1-5 \times 10^{6} \mathrm{cell} / \mathrm{mL}$ for yeasts and bacteria. The working suspension of the yeasts and bacteria was prepared by making a $1 / 1000$ and $1 / 100$ dilution of their stock suspension with appropriate broth media, respectively. After adding $0.1 \mathrm{~mL}$ of the working inoculums to each well, the plates were incubated in a humid atmosphere at $32^{\circ} \mathrm{C}$ for $24-48 \mathrm{~h}$ and $37^{\circ} \mathrm{C}$ for $24 \mathrm{~h}$ for the yeasts and bacteria, respectively. The wells of the first column of the microtiter plate (containing $200 \mu \mathrm{L}$ of the uninoculated medium) were considered as a sterility control (blank). Growth controls containing medium with inoculums without the nanoparticle were also used. The lowest concentration of the nanoparticle showing no visible growth was defined as MIC. Each experiment was done in triplicate.

2.3. Biofilm Preparation and Growth. Standard strains of microorganism including C. albicans (CBS 10261), C. dubliniensis (777), S. mutans (ATCC35668), S. sobrinus (ATCC27607), S. salivarius (ATCC9222), and S. sanguis (ATCC 2908) were cultured on appropriate media. Standard strains of bacteria and yeast were seeded on brain heart infusion agar and Sabouraud dextrose agar (Merck, Germany), respectively, and incubated at $35 \pm 2^{\circ} \mathrm{C}$ between 18 and $24 \mathrm{~h}$. After 24 hours, one loop of yeast and bacteria colonies was transferred to $20 \mathrm{~mL}$ Sabouraud dextrose and brain heart infusion broth, respectively, and incubated overnight in an orbital shaker $(100 \mathrm{rpm})$ at $30^{\circ} \mathrm{C}$ under an aerobic condition. Yeast and bacteria cells were then harvested and washed twice in sterile phosphate-buffered saline (PBS, $0.8 \% \mathrm{w} / \mathrm{v})$, sodium chloride $(0.02 \% \mathrm{w} / \mathrm{v}$, Merck, Germany), $\mathrm{KH}_{2} \mathrm{PO}_{4} \quad(0.31 \%$ w/v, Merck, Germany $)$, $\mathrm{Na}_{2} \mathrm{HPO}_{4} \cdot 12 \mathrm{H}_{2} \mathrm{O}(0.02 \%$ w/v, Merck, Germany), and $\mathrm{KCl}$ (Panreac, Madrid, Spain) with pH 7.4. Then, the cell densities were adjusted at $0.5 \mathrm{McF}$ arland standards by a spectrophotometric method. In order to determine the inhibitory effect on the biofilm formation of Candida and oral Streptococcus, 24-cell culture microtiter plates were used. For Candida species, $1 \mathrm{~mL}$ of RPMI-1640 was added into the first and $0.5 \mathrm{~mL}$ to the other columns. Then, resin disks containing different concentrations of nanoparticles (sterilized with UV rays) were placed into the appropriate wells. To assess the potential of the resin disks with nanoparticles on the mentioned bacteria strains biofilm formation, an overnight culture of each was grown in tryptic soy broth (TSB, Merck, Germany) for 18 to 20 hours at $37^{\circ} \mathrm{C}$. The suspensions were adjusted with TSB to $0.5 \mathrm{McFarland}$ as measured by absorbance ( 0.08 to 0.1 at $625 \mathrm{~nm}$ ) in a spectrophotometer corresponding to approximately $10^{8} \mathrm{CFU} \mathrm{mL} \mathrm{m}^{-1}$. Exposure of Candida and nanoparticles was performed as done for bacteria. Then, the plates were placed at $30^{\circ} \mathrm{C}$ for $48 \mathrm{~h}$ to form biofilm (Figure 1). After 48 hours, the plates were moved out of the incubator; the contents of each well were expelled and washed twice with sterile phosphate buffered saline.

2.4. Assessing Biofilm Formation. Biofilm formation was assayed by using a 2,3-bis(2-methoxy-4-nitro-5-sulfo-phenyl)-2H-tetrazolium-5-carbox-anilide (XTT, Sigma, USA) reduction assay. The XTT was prepared as a saturated solution at a concentration of $0.5 \mathrm{mg} \mathrm{mL}^{-1}$ in Ringer's lactate. The solution was filter-sterilized through a $0.22 \mu \mathrm{m}$ pore size filter, divided into aliquots, and then stored at $-70^{\circ} \mathrm{C}$. Prior to each assay, an aliquot of the XTT stock solution was thawed and treated with menadione sodium bisulfite $\left(10 \mathrm{mmol} \mathrm{L}{ }^{-1}\right.$ prepared in distilled water; Sigma, USA) to obtain a final concentration of $1 \mu \mathrm{mol} \mathrm{L}{ }^{-1}$ of menadione. A $500 \mu \mathrm{L}$ aliquot of XTT-menadione was then added to each prewashed biofilm and wells that contained disks (5 disks for each microorganism) treated with $\mathrm{CuO}$ and $\mathrm{TiO}_{2}$ nanoparticles and incubated for $4 \mathrm{~h}$ at $35^{\circ} \mathrm{C}$ in dark to measure background XTT levels. After adding $500 \mu \mathrm{L}$ of the prepared compound of XTT-menadione, the content of the wells was transferred to another plate and their spectral absorbance at a wavelength of $570 \mathrm{~nm}$ was evaluated by a multiwell scanning spectrophotometer (POLARstar Omega, Germany). All trials were performed in triplicate to maximally reduce the error rate [23]. Resin disks without nanoparticles in wells containing media and organism were used as positive control, while resin disks in wells with media served as the negative controls. Inhibition of biofilm formation was calculated as follows:

$$
\frac{\text { optical density of the growth control }- \text { optical density of the sample }}{\text { optical density of the growth control }} \times 100 \text {. }
$$

2.5. Data Analysis. Data were analyzed by using SPSS software (v.24, IBM product, Chicago, IL, USA). Numerical data were presented as means and standard deviations, explored for normality by using Kolmogorov-Smirnov test. ANOVA and Tukey's post hoc tests were used as appropriate $(\alpha=0.05)$.

\section{Results}

Nanoparticles of $\mathrm{CuO}$ and $\mathrm{TiO}_{2}$ successfully inhibited the growth of the tested standard strains of yeast and bacteria at concentrations ranging from 32 to $64 \mu \mathrm{g} \mathrm{mL}^{-1}$. Means and standard deviations of optical density and biofilm 


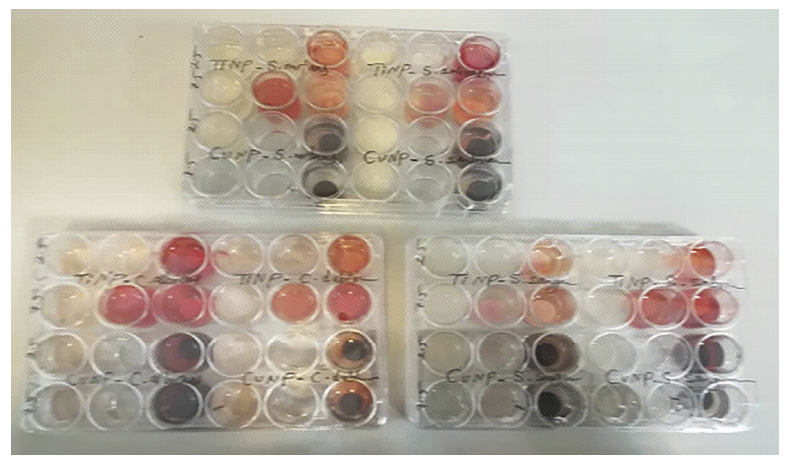

FIGURE 1: 24-cell plates containing acrylic specimens.

inhibition of the study groups for each strain of Streptococcus and Candida are presented in Tables 1 and 2. The higher optical density and lower percentage of biofilm inhibition shows lower antimicrobial activity against specific strain.

The result of one-way ANOVA revealed significantly different optical density values (antimicrobial activity) among the groups against all strains of Streptococcus (mutans $(P<0.001)$, sobrinus $(P<0.001)$, salivarius $(P<0.001)$, and sanguis $(P=0.002))$ and Candida (albicans $(P=0.045)$ and dubliniensis $(P<0.001))$. Tukey's post hoc tests showed that both concentrations of $\mathrm{CuO}$ had significantly higher antimicrobial activity against $S$. mutans than the control and $\mathrm{TiO}_{2}$ nanoparticle groups. However, the two concentrations of $\mathrm{CuO}$ nanoparticles were not significantly different $(P=0.986)$. Nor was any significant difference between $2.5 \% \mathrm{TiO}_{2}(P=0.316)$ and $7.5 \% \mathrm{TiO}_{2}(P=0.173)$ and the control group (Figure 2).

Concerning the $S$. sobrinus, $2.5 \% \mathrm{TiO}_{2}$ had significantly higher antimicrobial effect than both the control $(P=0.006)$ and $2.5 \% \mathrm{CuO}$ group $(P=0.001)$. Increasing the concentration of $\mathrm{CuO}$ from $2.5 \%$ to $7.5 \%$ significantly improved its antimicrobial effect $(P<0.001)$. Regarding the $S$. salivarius, both concentrations of both nanoparticles had significantly higher antimicrobial activity compared with the control group $\left(2.5 \% \mathrm{TiO}_{2}(P<0.001), 7.5 \% \mathrm{TiO}_{2}(P<0.001), 2.5 \%\right.$ $\mathrm{CuO}(P<0.001)$, and $7.5 \% \mathrm{CuO}(P<0.001))$. Considering the $S$. sanguis, all groups had significantly higher antimicrobial activity than the control group $\left(2.5 \% \quad \mathrm{TiO}_{2}\right.$ $(P=0.021), 7.5 \% \mathrm{TiO}_{2}(P=0.004), 2.5 \% \mathrm{CuO}(P<0.020)$, and $7.5 \% \mathrm{CuO}(P<0.02)$, with no significant difference among the nanoparticles $(P>0.05)$. Relating to $C$. albicans, only $7.5 \% \mathrm{TiO}_{2}$ had significantly higher antimicrobial activity than the control group $(P=0.043)$. For C. dubliniensis, both concentrations of both nanoparticles had significantly higher antimicrobial activity than the control group $(2.5 \%$ $\begin{array}{lllll}\mathrm{TiO}_{2} & (P=0.003), \quad 7.5 \% & \mathrm{TiO}_{2} \quad(P=0.002), \quad 2.5 \% \quad \mathrm{CuO}\end{array}$ $(P=0.001)$, and $7.5 \% \mathrm{CuO}(P<0.001))$ with no significant difference between the two concentrations of nanoparticles $(P>0.05)$ (Figure 3).

\section{Discussion}

The null hypothesis was rejected as adding different concentrations of $\mathrm{TiO}_{2}$ and $\mathrm{CuO}$ nanoparticles affected the antimicrobial properties of PMMA denture base resin after thermocycling. Many factors affect the adhesion of microorganisms and biofilm formation on the surfaces of acrylic resins, such as surface roughness, porosity, continual denture wearing, and poor denture hygiene [6]. This material is susceptible to colonization by various microbial species including C. albicans, C. glabrata, and Grampositive/negative organisms [13], necessitating the development of a denture with self-antimicrobial features. Oral temperature changes might be affected by routine activities like eating, drinking, breathing, and heat pressures that cause aging in denture and alter its properties. Like no other previous study, the present one considered these temperature changes to the acrylic specimens through thermocycling.

4.1. $P M M A+C u O$. The present results showed that both concentrations of $\mathrm{CuO}$ nanoparticles had significant antimicrobial activity against almost all strains of Streptococcus and C. dubliniensis. Similarly, Argueta-Figueroa et al. [18] confirmed the bactericidal effect of $\mathrm{Cu}$ nanoparticle against S. aureus, E. coli, and S. mutans. Ahamed et al. [24] detected that $\mathrm{CuO}$ nanoparticles could be externally used as antibacterial agents in surface coatings on various substrates to prevent microorganisms from attaching, colonizing, spreading, and forming biofilms in indwelling medical devices. It also had excellent antimicrobial activity against various bacterial strains (Escherichia coli, Pseudomonas aeruginosa, Klebsiella pneumonia, and Staphylococcus aureus). Benoit et al. [25] reported $\mathrm{CuO}$ nanoparticles as proper alternatives to control biofilm formation within the oral cavity.

In this study, neither concentration of $\mathrm{CuO}$ nanoparticles affected the antimicrobial activity against C. albicans. This was in agreement with the study conducted by Amiri et al. [20], which showed that nanocopper oxide had high antimicrobial effect against the examined dental caries bacterial agents and lower effect on the three species of Candida. Another study showed that the antimicrobial action of $\mathrm{CuO}$ nanoparticles on all the three species of C. albicans, C. krusei, and C. glabrata was not as effective as that on cariogenic bacteria; yet they might be good candidate control agents for preventing cariogenic activity and other dental infections [26]. The antimicrobial 
TABLE 1: Means \pm standard deviations, biofilm inhibition (\%), and multiple comparisons of optical density of the study groups for bacteria species.

\begin{tabular}{|c|c|c|c|c|c|}
\hline \multirow{2}{*}{ Groups } & \multirow{2}{*}{ Factors } & \multicolumn{4}{|c|}{ Bacteria species } \\
\hline & & S. mutans & S. sobrinus & S. salivarius & S. sanguis \\
\hline \multirow{2}{*}{$2.5 \% \mathrm{TiO}_{2}$} & Optical density & $0.70 \pm 0.02^{\mathrm{cd}}$ & $1.66 \pm 0.23^{\mathrm{a}}$ & $0.69 \pm 0.00^{\mathrm{a}}$ & $0.51 \pm 0.07^{\mathrm{a}}$ \\
\hline & Biofilm inhibition & $25 \%$ & $48 \%$ & $80 \%$ & $70 \%$ \\
\hline \multirow{2}{*}{$7.5 \% \mathrm{TiO}_{2}$} & Optical density & $0.42 \pm 0.06^{\mathrm{bc}}$ & $1.78 \pm 0.09^{\mathrm{a}}$ & $0.28 \pm 0.01^{\mathrm{b}}$ & $0.27 \pm 0.07^{\mathrm{a}}$ \\
\hline & Biofilm inhibition & $18 \%$ & $43.7 \%$ & $93 \%$ & $79 \%$ \\
\hline \multirow{2}{*}{$2.5 \% \mathrm{CuO}$} & Optical density & $0.19 \pm 0.03^{\mathrm{ab}}$ & $3.70 \pm 0.21^{\mathrm{b}}$ & $0.58 \pm 0.12^{\mathrm{ab}}$ & $0.50 \pm 0.13^{\mathrm{a}}$ \\
\hline & Biofilm inhibition & $60 \%$ & $6 \%$ & $83 \%$ & $44 \%$ \\
\hline \multirow{2}{*}{$7.5 \% \mathrm{CuO}$} & Optical density & $0.17 \pm 0.07^{\mathrm{a}}$ & $0.34 \pm 0.06^{\mathrm{c}}$ & $0.34 \pm 0.06^{\mathrm{b}}$ & $0.18 \pm 0.01^{\mathrm{a}}$ \\
\hline & Biofilm inhibition & $66 \%$ & $89 \%$ & $90 \%$ & $80 \%$ \\
\hline Control & Optical density & $0.58 \pm 0.08^{\mathrm{c}}$ & $3.00 \pm 0.24^{\mathrm{b}}$ & $3.16 \pm 0.09^{c}$ & $0.99 \pm 0.08^{\mathrm{b}}$ \\
\hline
\end{tabular}

Vertically within groups, different superscript lowercase letters indicate significant differences between groups in the same column $(P \leq 0.05)$.

TABLE 2: Means \pm standard deviations, biofilm inhibition (\%), and multiple comparisons of optical density of the study groups for Candida species.

\begin{tabular}{lccc}
\hline \multirow{2}{*}{ Groups } & \multirow{2}{*}{ Factors } & \multicolumn{2}{c}{ Candida species } \\
& & C. albicans & C. dubliniensis \\
\hline \multirow{2}{*}{$2.5 \% \mathrm{TiO}_{2}$} & Optical density & $1.98 \pm 0.16^{\mathrm{a}, \mathrm{b}}$ & $0.84 \pm 0.07^{\mathrm{a}}$ \\
& Biofilm inhibition & $3 \%$ & $46 \%$ \\
\hline \multirow{2}{*}{$7.5 \% \mathrm{TiO}_{2}$} & Optical density & $1.43 \pm 0.18^{\mathrm{a}}$ & $0.74 \pm 0.08^{\mathrm{a}, \mathrm{b}}$ \\
& Biofilm inhibition & $31 \%$ & $56 \%$ \\
\hline \multirow{2}{*}{$2.5 \% \mathrm{CuO}$} & Optical density & $1.81 \pm 0.12^{\mathrm{a}, \mathrm{b}}$ & $0.54 \pm 0.08^{\mathrm{a}, \mathrm{b}}$ \\
& Biofilm inhibition & $13 \%$ & $66 \%$ \\
\hline \multirow{2}{*}{$7.5 \% \mathrm{CuO}$} & Optical density & $1.72 \pm 0.11^{\mathrm{a}, \mathrm{b}}$ & $0.42 \pm 0.10^{\mathrm{b}}$ \\
& Biofilm inhibition & $18 \%$ & $73 \%$ \\
\hline Control & Optical density & $2.04 \pm 0.12^{\mathrm{b}}$ & $1.62 \pm 0.14^{\mathrm{c}}$ \\
\hline
\end{tabular}

Vertically within groups, different superscript lowercase letters indicate significant differences between groups in the same column $(P \leq 0.05)$.

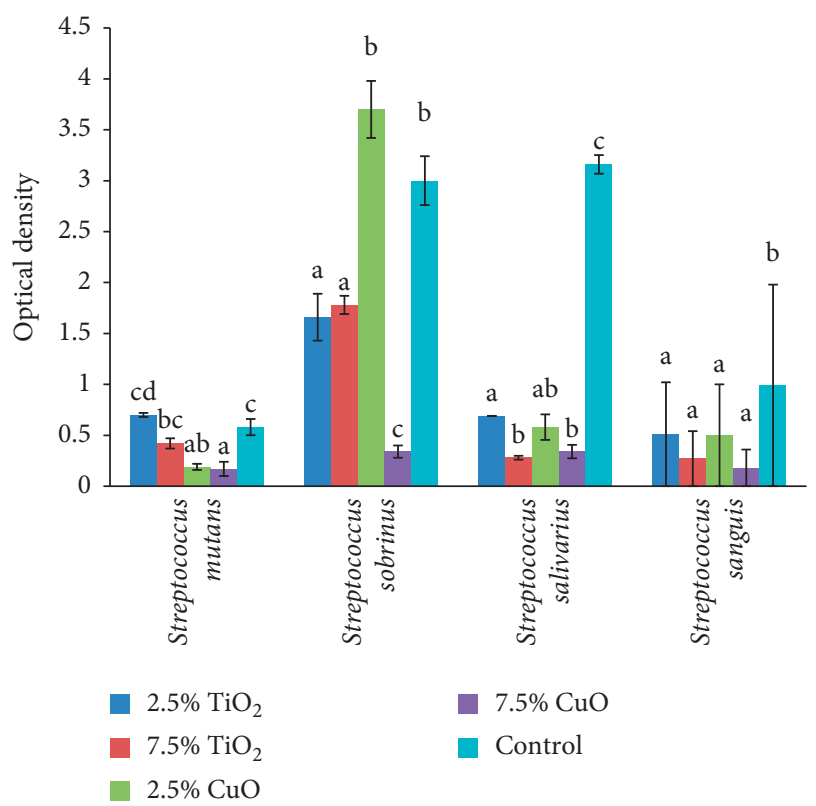

FIGURE 2: Means and standard deviations $(n=5)$ of optical density of the study groups against different strains of Streptococcus.

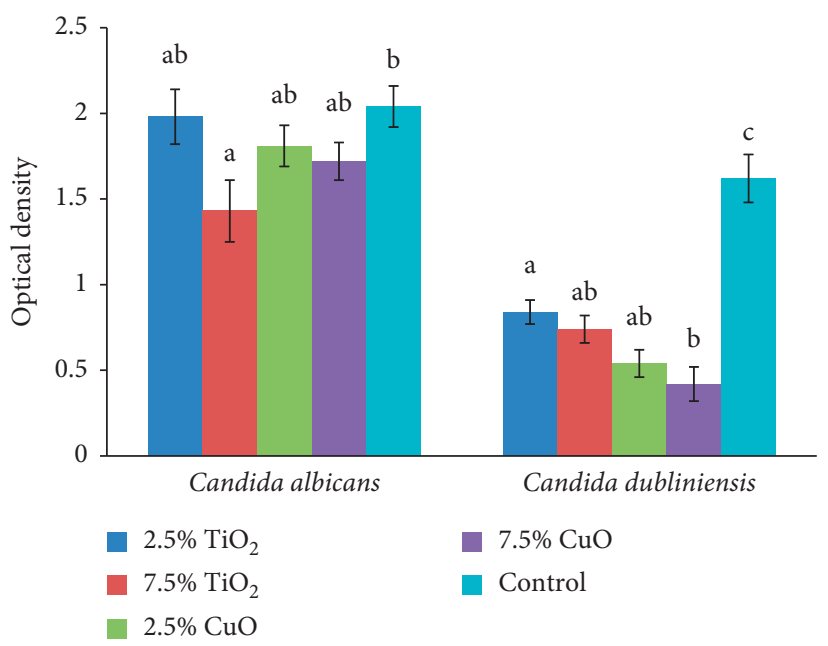

Figure 3: Means and standard deviations $(n=5)$ of optical density of the study groups against different strains of Candida.

activity of $\mathrm{CuO}$ nanoparticles is due to their close interaction with microbial membranes and the release of metal ions. The nanoparticles are slowly oxidized, release copper ions, and produce toxic hydroxyl free radicals when close to the lipid membrane. Free radicals separate the lipids from the cell membrane through oxidation and destroy the membrane [27].

4.2. $P M M A+\mathrm{TiO}_{2}$. This study found that neither concentration of $\mathrm{TiO}_{2}$ had significant effect against S. mutans. Moreover, both concentrations of $\mathrm{TiO}_{2}$ nanoparticles had significant antimicrobial activity against $S$. salivarius, S. sanguis, and C. dubliniensis. Concerning the C. albicans, $7.5 \% \mathrm{TiO}_{2}$ was the only nanoparticle with significant antimicrobial effect. This was consistent with Abdulrazzaq Naji et al.'s study [13], which suggested $\mathrm{PMMA} / \mathrm{TiO}_{2}$ nanotube composite as a promising material for antimicrobial approaches. Another study showed that adding $3 \mathrm{wt} \% \mathrm{TiO}_{2}$ nanoparticles to PMMA produced a positive antimicrobial effect, reduced the microbial number, which prevented quorum sensing, and thereby halted plaque formation on $\mathrm{PMMA} / \mathrm{TiO}_{2}$ nanocomposite surface [28]. Likewise, Gad 
and Abualsaud [29] showed that all concentrations of $\mathrm{TiO}_{2}$ nanoparticles $(0.4 \%, 1 \%$, and $2.5 \%)$ inhibited the growth of Candida.

$\mathrm{TiO}_{2}$ nanoparticles have an intrinsic antimicrobial property due to the production of cytotoxic oxygen radicals. When exposed to UV-light in the presence of oxygen and water, these particles decompose and oxidize other organic and inorganic compounds [11]. Therefore, they can be considered as antimicrobial additive. The integration of $\mathrm{TiO}_{2}$ nanoparticles to PMMA reduces the porosity of the denture bases. Besides, $\mathrm{TiO}_{2}$ nanoparticles inhibit the adherence of cariogenic bacteria in planktonic phase and further phases of biofilm formation [30]. Hence, increasing the $\mathrm{TiO}_{2}$ ratio in PMMA-TiO ${ }_{2}$ improves the antimicrobial activity of PMMA by drastically decreasing bacterial adherence [29].

Alrahlah et al. [8] found that adding only $3 \% \mathrm{TiO}_{2}$ nanoparticles decreased the bacterial cell attachment of E. faecalis and $P$. aeruginosa by 50 to $90 \%$. A different study reported that coating the implants with $\mathrm{TiO}_{2}$ nanoparticles inhibited the adhesion and growth of bacteria such as S. mutans, S. epidermis, and E. coli, besides preventing the inflammation around the implants [14]. A significant reduction was also noted in bacterial adhesion and colonization of S. mutans, S. salivarius, and S. sanguis on anatase-coated titanium of dental implant abutments [31].

Increasing the concentration of $\mathrm{TiO}_{2}$ from $2.5 \%$ to $7.5 \%$ did not significantly increase the antimicrobial effect against S. sobrinus, S. sanguis, C. albicans, and C. dubliniensis. It was in line with Totu et al.'s study [32], which found that incorporating even small amounts of $0.4 \% \mathrm{TiO}_{2}$ nanoparticles to a 3D-printed PMMA denture prevented the colonization of microorganisms and further biofilm formation. Another study showed that adding $\mathrm{TiO}_{2}$ and $\mathrm{SiO}_{2}$ nanoparticles $(0.5 \%$ and $1 \%)$ to PMMA imparted antimicrobial activity to the resins, being even more efficient under UVA exposure [33].

According to the present findings, the clinicians and technicians are suggested to add either $2.5 \%$ or $7.5 \%$ of $\mathrm{CuO}$ in combination with $7.5 \% \mathrm{TiO}_{2}$ nanoparticle to heat-cured PMMA denture bases and improve the antimicrobial activity of dentures against almost all species of the Candida and Streptococcus, which are the most common microorganisms colonized on denture base materials.

The limitation of this study was assessing only two concentrations of the two types of nanoparticles. Moreover, the antimicrobial effect of these nanoparticles was not evaluated in the clinical situation in presence of saliva. Further studies are recommended to evaluate the antimicrobial properties of other concentrations and types of nanoparticles and the combination of these nanoparticles against different oral microorganism in the clinical situations.

\section{Conclusions}

Considering the findings and limitations of the present study, the following can be concluded:

(1) Adding both $2.5 \%$ and $7.5 \%$ concentrations of $\mathrm{CuO}$ and $\mathrm{TiO}_{2}$ nanoparticles to heat-cured PMMA denture base material can obviously increase the antimicrobial activity against S. salivarius, S. sanguis, and C. dubliniensis

(2) Both concentrations of $\mathrm{CuO}$ nanoparticles can significantly improve the antimicrobial activity of PMMA against $S$. mutans; however, $\mathrm{TiO}_{2}$ nanoparticles do not alter the antimicrobial activity of PMMA against $S$. mutans

(3) Concerning C. albicans, $7.5 \% \mathrm{TiO}_{2}$ is the only nanoparticle that can increase the antimicrobial activity of PMMA against this microorganism

(4) Adding $2.5 \%$ or $7.5 \%$ concentrations of $\mathrm{CuO}$ nanoparticles in combination with $7.5 \% \mathrm{TiO}_{2}$ to heat-cured PMMA denture base materials can effectively inhibit the growth of different species of Streptococcus and Candida

\section{Data Availability}

All the data used to support the findings of this study are available from the corresponding author upon request.

\section{Disclosure}

This article was based on the thesis of Sedigheh Rahmannasab in partial fulfilment of DMD degree.

\section{Conflicts of Interest}

The authors declare that they have no conflicts of interest regarding the publication of this paper.

\section{Acknowledgments}

The authors would like to thank the Vice Chancellery of Research, Shiraz University of Medical Sciences, for financially supporting this research (Grant no. 98-01-03-20953). Appreciation is also due to Ms. Farzaneh Rasouli for improving the English language of this manuscript and Dr. Seyed Ali Tabei for helping with the statistical analysis.

\section{References}

[1] M. Fukunishi, Y. Inoue, H. Morisaki et al., "A polymethyl methacrylate-based acrylic dental resin surface bound with a photoreactive polymer inhibits accumulation of bacterial plaque," The International Journal of Prosthodontics, vol. 30, no. 6, pp. 533-540, 2017.

[2] I. Sivakumar, K. S. Arunachalam, S. Sajjan, A. V. Ramaraju, B. Rao, and B. Kamaraj, "Incorporation of antimicrobial macromolecules in acrylic denture base resins: a research composition and update," Journal of Prosthodontics, vol. 23, no. 4, pp. 284-290, 2014.

[3] H. Akin, F. Tugut, and Z. A. Polat, "In vitro comparison of the cytotoxicity and water sorption of two different denture base systems," Journal of Prosthodontics, vol. 24, no. 2, pp. 152-155, 2015.

[4] I. Machado de Andrade, P. C. Cruz, C. H. Silva-Lovato, R. F. de Souza, M. Cristina Monteiro Souza-Gugelmin, and H. de Freitas Oliveira Paranhos, "Effect of chlorhexidine on denture biofilm accumulation," Journal of Prosthodontics, vol. 21, no. 1, pp. 2-6, 2012. 
[5] M. Tsuji, T. Ueda, K. Sawaki, M. Kawaguchi, and K. Sakurai, "Biocompatibility of a titanium dioxide-coating method for denture base acrylic resin," Gerodontology, vol. 33, no. 4, pp. 539-544, 2016.

[6] L. Gendreau and Z. G. Loewy, "Epidemiology and etiology of denture stomatitis," Journal of Prosthodontics, vol. 20, no. 4, pp. 251-260, 2011.

[7] G. Nazirkar, S. Bhanushali, S. Singh, B. Pattanaik, and N. Raj, "Effect of anatase titanium dioxide nanoparticles on the flexural strength of heat cured poly methyl methacrylate resins: an in-Vitro Study," The Journal of Indian Prosthodontic Society, vol. 14, no. S1, pp. 144-149, 2014.

[8] A. Alrahlah, H. Fouad, M. Hashem, A. Niazy, and A. AlBadah, "Titanium oxide ( $\mathrm{TiO} 2) /$ polymethylmethacrylate (PMMA) denture base nanocomposites: mechanical, viscoelastic and antibacterial behavior," Materials, vol. 11, no. 7, p. 1096, 2018.

[9] S. Suganya, S. Ahila, B. Kumar, and M. Kumar, "Evaluation and comparison of anti-Candida effect of heat cure polymethylmethacrylate resin enforced with silver nanoparticles and conventional heat cure resins: an in vitro study," Indian Journal of Dental Research, vol. 25, no. 2, pp. 204-207, 2014.

[10] R. M. Abdallah, "Evaluation of polymethyl methacrylate resin mechanical properties with incorporated halloysite nanotubes," The Journal of Advanced Prosthodontics, vol. 8, no. 3, pp. 167-171, 2016.

[11] J. Jaison, A. Barhoum, Y. S. Chan, A. Dufresne, and M. K. Danquah, "Review on nanoparticles and nanostructured materials: history, sources, toxicity and regulations," Beilstein J Nanotechnol, vol. 9, pp. 1050-1074, 2018.

[12] M. A. Gatoo, S. Naseem, M. Y. Arfat, A. Mahmood Dar, K. Qasim, and S. Zubair, "Physicochemical properties of nanomaterials: implication in associated toxic manifestations," BioMed Research International, vol. 2014, Article ID 498420, 8 pages, 2014.

[13] S. Abdulrazzaq Naji, T. S. J. Kashi, M. Pourhajibagher, M. Behroozibakhsh, R. Masaeli, and A. Bahador, "Evaluation of antimicrobial properties of conventional poly (methyl methacrylate) denture base resin materials containing hydrothermally synthesised anatase $\mathrm{TiO}_{2}$ nanotubes against cariogenic bacteria and candida albicans," Iranian Journal of Pharmaceutical Research, vol. 17, pp. 161-172, 2018.

[14] A. Sodagar, A. Bahador, S. Khalil, A. Saffar Shahroudi, and M. Zaman Kassaee, "The effect of $\mathrm{TiO} 2$ and $\mathrm{SiO} 2$ nanoparticles on flexural strength of poly (methyl methacrylate) acrylic resins," Journal of Prosthodontic Research, vol. 57, no. 1, pp. 15-19, 2013.

[15] M. T. A. Aydın, H. L. Hoşgün, A. Dede, and K. Güven, "Synthesis, characterization and antibacterial activity of silver-doped TiO2 nanotubes," Spectrochim Acta A Mol Biomol Spectrosc, vol. 205, pp. 503-507, 2018.

[16] M. T. El-Saadony, M. E. Abd El-Hack, A. E. Taha et al., "Ecofriendly synthesis and insecticidal application of copper nanoparticles against the storage pest Tribolium castaneum," Nanomaterials, vol. 10, no. 3, pp. 587-603, 2020.

[17] A. El-Trass, H. ElShamy, I. El-Mehasseb, and M. El-Kemary, "CuO nanoparticles: synthesis, characterization, optical properties and interaction with amino acids," Applied Surface Science, vol. 258, no. 7, pp. 2997-3001, 2012.

[18] L. Argueta-Figueroa, R. A. Morales-Luckie, R. J. ScougallVilchis, and O. F. Olea-Mejía, "Synthesis, characterization and antibacterial activity of copper, nickel and bimetallic $\mathrm{Cu}$ $\mathrm{Ni}$ nanoparticles for potential use in dental materials," Progress in Natural Science: Materials International, vol. 24, no. 4, pp. 321-328, 2014.
[19] R. Chen, Z. Han, Z. Huang et al., "Antibacterial activity, cytotoxicity and mechanical behavior of nano-enhanced denture base resin with different kinds of inorganic antibacterial agents," Dental Materials Journal, vol. 36, no. 6, pp. 693-699, 2017.

[20] M. Amiri, Z. Etemadifar, A. Daneshkazemi, and M. Nateghi, "Antimicrobial effect of copper oxide nanoparticles on some oral bacteria and candida species," Journal of Dental Biomaterials, vol. 4, no. 1, pp. 347-352, 2017.

[21] S. Abdulrazzaq Naji, M. Behroozibakhsh, T. S. Jafarzadeh Kashi et al., "Effects of incorporation of 2.5 and 5 wt $\%$ TiO2 nanotubes on fracture toughness, flexural strength, and microhardness of denture base poly methyl methacrylate (PMMA)," ournal of Advanced Prosthodontics, vol. 10, pp. 113-121, 2018.

[22] M. M. Gad, R. Abualsaud, A. M. Al-Thobity, N. Z. Baba, and F. A. Al-Harbi, "Influence of addition of different nanoparticles on the surface properties of poly(methylmethacrylate) denture base material," Journal of Prosthodontics, vol. 29, no. 5, pp. 422-428, 2020.

[23] K. Zomorodian, J. Saharkhiz, K. Pakshir, Z. Immeripour, and A. Sadatsharifi, "The composition, antibiofilm and antimicrobial activities of essential oil of Ferula assa-foetida oleogum-resin," Biocatalysis and Agricultural Biotechnology, vol. 14, pp. 300-304, 2018.

[24] M. Ahamed, H. A. Alhadlaq, M. A. M. Khan, P. Karuppiah, and N. A. Al-Dhabi, "Synthesis, characterization, and antimicrobial activity of copper oxide nanoparticles," Journal of Nanomaterials, vol. 2014, Article ID 637858, 4 pages, 2014.

[25] D. S. W. Benoit, K. R. Sims Jr, and D. Fraser, "Nanoparticles for oral biofilm treatments," ACS Nano, vol. 13, no. 5, pp. 4869-4875, 2019.

[26] N. Ahmad, Z. Jafri, and Z. H. Khan, "Evaluation of nanomaterials to prevent oral Candidiasis in PMMA based denture wearing patients. A systematic analysis," Journal of Oral Biology and Craniofacial Research, vol. 10, no. 2, pp. 189-193, 2020.

[27] L. Wang, C. Hu, and L. Shao, "The antimicrobial activity of nanoparticles: present situation and prospects for the future," International Journal of Nanomedicine, vol. 12, p. 1227, 2017.

[28] R. D. Kulkarni, G. V. Anehosur, M. G. Naik, and R. K. Nadiger, "Synthesis and determination of antimicrobial activity of visible light activated $\mathrm{TiO}_{2}$ nanoparticles with polymethyl methacrylate denture base resin against staphylococcus aureus," Journal of Gerontology \& Geriatric Research, vol. 1, 2012.

[29] M. M. Gad and R. Abualsaud, "Behavior of PMMA denture base materials containing titanium dioxide nanoparticles: a literature review," International Journal of Biomaterials, vol. 2019, pp. 1-14, 2019.

[30] A. Bahador, S. Khalil, B. Pourakbari et al., "Photocatalytic effects of acrylic resins incorporated with Nano-titanium dioxide on planktonic and biofilm growth of four cariogenic bacteria," Annual Research \& Review in Biology, vol. 4, no. 17, pp. 2695-2708, 2014.

[31] A. Scarano, A. Piattelli, A. Polimeni, D. Di Iorio, and F. Carinci, "Bacterial adhesion on commercially pure titanium and anatase-coated titanium healing screws: an in vivo human study," Journal of Periodontology, vol. 81, no. 10, pp. 1466-1471, 2010.

[32] E. E. Totu, A. C. Nechifor, G. Nechifor, H. Y. Aboul-Enein, and C. M. Cristache, "Poly(methyl methacrylate) with $\mathrm{TiO}_{2}$ nanoparticles inclusion for stereolitographic complete denture manufacturing-the fututre in dental care for elderly 
edentulous patients?" Journal of Dentistry, vol. 59, pp. 68-77, 2017.

[33] A. Sodagar, S. Khalil, M. Z. Kassaee, A. S. Shahroudi, B. Pourakbari, and A. Bahador, "Antimicrobial properties of poly (methyl methacrylate) acrylic resins incorporated with silicon dioxide and titanium dioxide nanoparticles on cariogenic bacteria," Journal of Orthodontic Science, vol. 5, pp. 7-13, 2016. 